University of Nebraska - Lincoln

DigitalCommons@University of Nebraska - Lincoln

1998

Computer Model for Simulating Almond Moth (Lepidoptera:

Pyralidae) Population Dynamics

James E. Throne

USDA-ARS, Manhattan, KS, james.throne@ars.usda.gov

David W. Hagstrum

USDA-ARS

Jan Nawrot

Instytut Ochrony Roslin

Follow this and additional works at: https://digitalcommons.unl.edu/usdaarsfacpub

Throne, James E.; Hagstrum, David W.; and Nawrot, Jan, "Computer Model for Simulating Almond Moth (Lepidoptera: Pyralidae) Population Dynamics" (1998). Publications from USDA-ARS / UNL Faculty. 1994. https://digitalcommons.unl.edu/usdaarsfacpub/1994

This Article is brought to you for free and open access by the U.S. Department of Agriculture: Agricultural Research Service, Lincoln, Nebraska at DigitalCommons@University of Nebraska - Lincoln. It has been accepted for inclusion in Publications from USDA-ARS / UNL Faculty by an authorized administrator of DigitalCommons@University of Nebraska - Lincoln. 


\title{
Computer Model for Simulating Almond Moth (Lepidoptera: Pyralidae) Population Dynamics
}

\author{
JAMES E. THRONE, DAVID W. HAGSTRUM, AND JAN NAWROT
}

Grain Marketing and Production Research Center, USDA-ARS, 1515 College Avenue, Manhattan, KS 66502

\begin{abstract}
Environ. Entomol. 27(2): 344-354 (1998)
ABSTRACT We developed a computer model for simulating the population dynamics of the almond moth, Cadra cautella (Walker). The model incorporates previously published life history data for the almond moth developing on stored peanuts, Arachis hypogaea L., including stage-specific immature developmental time and survival and adult longevity and fecundity. The model was modified so that it also could be used to simulate almond moth population dynamics on stored, dried citrus pulp and stored corn (Zea mays L.). We tested the validity of the model by using 4 previously published data sets. The model was useful for interpreting population dynamics observed in the previously published studies and will be useful for optimizing management strategies for the almond moth.
\end{abstract}

KEY WORDS Cadra cautella, citrus pulp, corn, peanuts, population dynamics, simulation model

ThE ALMOND MOTH, Cadra cautella (Walker), is a cosmopolitan pest of stored grain and other stored products, particularly cocoa, Theobroma cacao L., dried nuts and fruits, and peanuts, Arachis hypogaea L. (de Abreu et al. 1982). Eggs are laid on or near stored products. The larvae feed on the stored products, damaging the product directly and forming webbing on the surface that may interfere with processing. Older larvae may leave the food and wander to find a pupation site. Adults are short-lived and do not feed on the stored products.

Many control methods have been tested or used for almond moths. Use of protectant insecticides has been the predominant control strategy for the last $30 \mathrm{yr}$ (Arthur 1989) but is now of limited usefulness because of problems with pest resistance to insecticides (Arthur et al. 1988). Fumigation with phosphine (Schesser 1977) or methyl bromide (Leesch et al. 1974) has been used to control existing infestations or sometimes on a regular schedule to prevent population increase, but the use of fumigants is becoming more restricted because of problems with environmental contamination. Other control strategies that have been tried experimentally but have not been widely used commercially are modified atmospheres (Storey 1975), irradiation (Amoako-Atta and Partida 1976), low (Donahaye et al. 1995) or high temperatures (Arbogast 1981), biological control (Keever et al. 1986), mating disruption with pheromones (Prevett et al. 1989), and host plant (or commodity) resistance (Rathore et al. 1980).

This article reports the results of research only. Mention of a proprietary product does not constitute an endorsement or recommendation for its use by USDA.

I Instytut Ochrony Roslin, UL. Miczurina 20, 60-318, Poznan, Poland.
It is difficult to determine whether an almond moth population will reach or has reached damaging levels and which control method, or combination of methods, will provide the best control. Depending on commodity, populations may be sampled by using sticky (Bowditch and Madden 1996) or light traps (Kirkpatrick et al. 1972), or by examining the commodity directly (Riley 1957). However, relating number of insects in the samples to actual population size may be difficult (Vick et al. 1990, White et al. 1990), and population levels at which stored commodities should be treated have not been well established for most commodities. Thus, protectant chemicals and routine fumigations often have been used to try to suppress almond moth populations, with varying degrees of success (Kirkpatrick et al. 1972). Therefore, computer models that simulate almond moth population development in stored commodities could be useful for predicting timing and levels of population peaks and for optimizing control strategies.

One of the essential components of a management model is a module for simulating the effects of environmental conditions on insect biology (Hagstrum and Throne 1989). Modules for simulating the effects of control strategies can then be developed and combined with the insect modules, and the resulting model can be used to investigate and optimize control strategies (Hagstrum and Flinn 1990). Development of population dynamics models can be particularly useful in identifying areas where further research is required to enhance understanding of observed population dynamics (Ruesink 1976).

Temperature, moisture, and diet are the main factors influencing insect development on stored commodities (Subramanyam and Hagstrum 1993) and should be included in a model for simulating almond 
moth population development. Nawrot (1979a) investigated the effects of temperature and relative humidity on immature developmental time and survival and adult longevity and fecundity of the almond moth on peanuts over the entire range of temperatures and relative humidities at which the insect survives. $\mathrm{He}$ also determined life history parameters of almond moths on other foods (Nawrot 1979b).

Our objectives were to use previously published data for almond moths on peanuts to develop a computer model for simulating the population dynamics of the almond moth on peanuts, to modify the model for use on other commodities, and to determine the validity of the model. Development and validation of the model would identify areas of research where further data are required to enhance the usefulness of the model as a management tool.

\section{Materials and Methods}

Model Development. The effects of temperature and relative humidity on immature developmental time and survival and adult longevity and fecundity of almond moths were described by equations fit using TableCurve 3D software (Jandel Scientific, San Rafael, CA). Equations were chosen for their fit and simplicity and because the shape of the response surface conformed to the general response to temperature and relative humidity of other insects. We had expectations of the general shape of the response surfaces based on data for other insects and ensured that the selected response surfaces met these expectations when we extrapolated beyond our data. We expected that developmental times and mortality of immatures would increase as temperature and relative humidity decreased below or increased above optimum levels. Adult longevity should increase and rate of fecundity should decrease as temperature and relative humidity decrease. Fit was determined by visual examination of plots of predicted and observed data (Figs. 1 and 2), and by $r^{2}$ values in Table 1. However, in interpreting $r^{2}$, one must consider whether any equation can fit the observed data well. For example, the data for duration of immature stages followed a consistent pattern as environmental conditions changed (Figs. $1 \mathrm{~A}-\mathrm{C}$ ), resulting in high $r^{2}$ values for these equations. Data for mortality of immature stages (Fig, 1. D-F) and for adult fecundity and longevity (Fig. 2) were less consistent as environmental conditions changed, and this inconsistency is reflected in the lower $r^{2}$ values. We did not try to increase $r^{2}$ values by fitting inconsistencies in the data as environmental conditions changed.

Variation in developmental time was simulated with a time-varying distributed delay (Manetsch 1976). The basis for this method is that the shape of the curve describing the number of individuals leaving a stage over time can be approximated by a member of the Erlang family of density functions. The specific function is designated by $K$ that is calculated as $\mu^{2} / \sigma^{2}$, where $\mu$ is mean development time of a stage at 1 environmental condition and $\sigma^{2}$ is the variance asso- ciated with that mean. When $K$ equals 1 , the function is an exponential distribution. As $K$ approaches infinity, the function approaches a discrete delay with a variance in developmental times of 0 . The value of $K$ was $11,159,29,7,9$, and 4 for the egg, larval, pupil, adult male, ovipositing adult female, and post-ovipositing adult female stages, respectively. The method for calculating $K$ for each stage was according to Throne (1989). Emerging adults were distributed at a 1:1 sex ratio. Time step in the model was $0.1 \mathrm{~d}$ (i.e., duration of development, survivorship, and fecundity were updated in the simulations every $0.1 \mathrm{~d}$ and environmental conditions were input every $0.1 \mathrm{~d}$ ).

Model Validation on Peanuts. We used published data sets to determine the validity of the model. The model simulates population development based on environmental conditions but does not simulate the effects of management strategies on insect populations. We made assumptions about the effects of the management strategies used in the validation studies based on descriptions in the published studies. However, we did not simulate the management strategies in the model, but rather we tried to mimic the effect that the management strategies had on the insect populations under the specific conditions of the study. The way that we mimicked the management strategies in this model would not be expected to be applicable to other management situations. For example, if the authors stated that $10 \%$ of larvae were killed by mites in their study, then we killed $10 \%$ of larvae in the simulations. To actually model the effects of mites on almond moth population dynamics, we would need to know the effects of environmental conditions on mite population development and on the interaction of mites and almond moths. Submodels for simulating management strategies will need to be added before the model can be used for making management decisions, and development of these submodels awaits the collection of data required for modeling management strategies. However, the current model can be used to determine when pest control is required.

Approximately 1.4 million metric tons of peanuts are grown in the United States each year (USDA 1994), with a production value of over $\$ 1$ billion. Most peanuts are used for peanut butter or candy, or are eaten directly. Peanuts are grown in the southern United States, harvested in fall, dried, and placed into storage. Peanuts may be moved into storage in a warehouse over a 1- to 2-mo period as harvest progresses. Protectant chemicals and fumigants are used to limit insect infestation levels in storage. Peanuts may be removed from storage over an extended period, depending upon processing needs.

We used 2 published data sets to determine the validity of the model for stored peanuts, and these data sets reported environmental conditions and estimates of almond moth population levels. Kirkpatrick et al. (1972) tested 2 types of light traps for monitoring adult moth activity in a peanut storage in Georgia fromı 11 October to 19 December 1965 . They found low levels of field infestation of the peanuts, so we assumed that the peanuts were infested by adults flying into the 

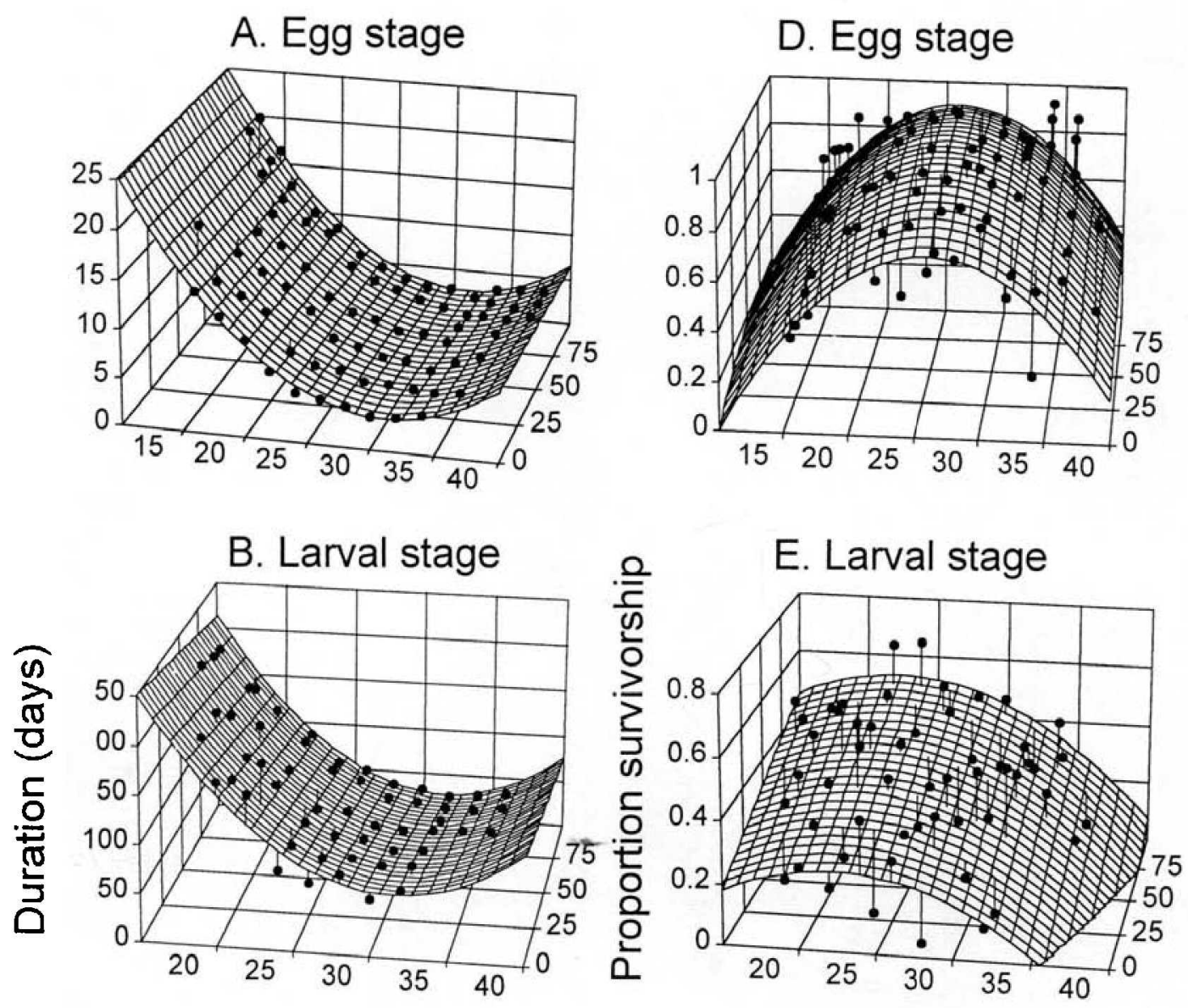

\section{Pupal stage}

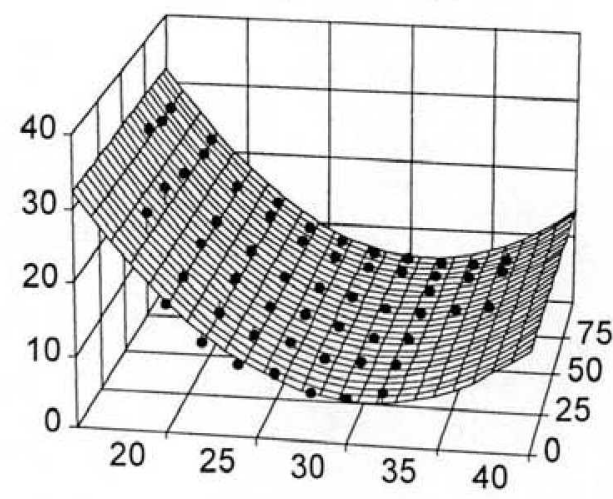

\section{F. Pupal stage}

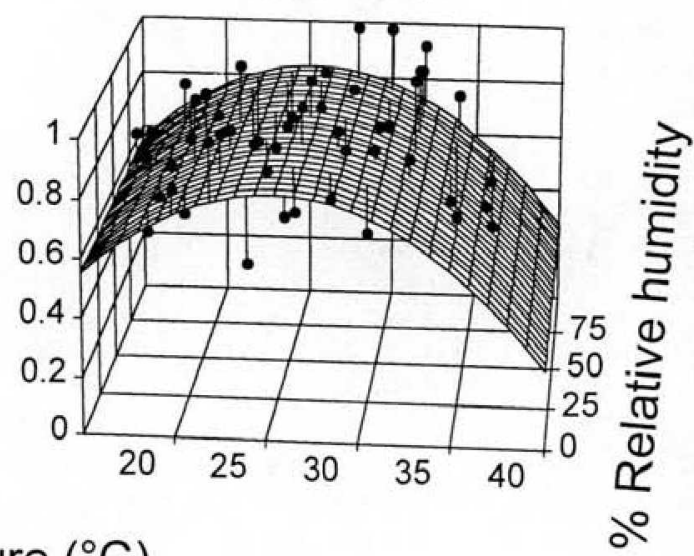

\section{Temperature $\left({ }^{\circ} \mathrm{C}\right)$}

Fig. 1. Effects of temperature and relative humidity on (A) duration of the egg stage; (B) duration of the larval stage; (C) duration of the pupal stage; (D) egg survivorship; (E) larval survivorship; and (F) pupal survivorship of C. cautella. Circles, observed data (from Nawrot 1979a); response surface, fitted equation (see Table 1). Drop lines indicate whether observed data are above or below the response surface, not standard errors.

warehouse. They began trapping and recording environmental conditions when the 1st adults emerged from the peanuts after $8 \mathrm{wk}$ of storage. We started the simulation by running the model for $8 \mathrm{wk}$ at $26^{\circ} \mathrm{C}$, choosing this temperature so that the 1st adults would emerge in the simulation after $8 \mathrm{wk}$ to match the lst emergence that Kirkpatrick et al. (1972) observed in the warehouse. Observed mean air temperature in the 
A. Male

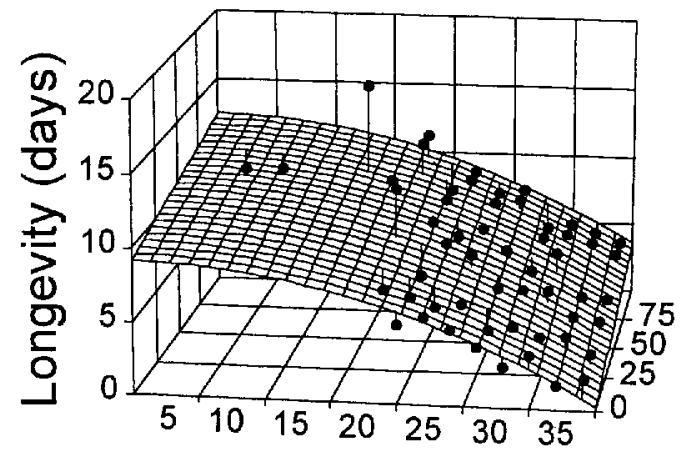

B. Oviposition period

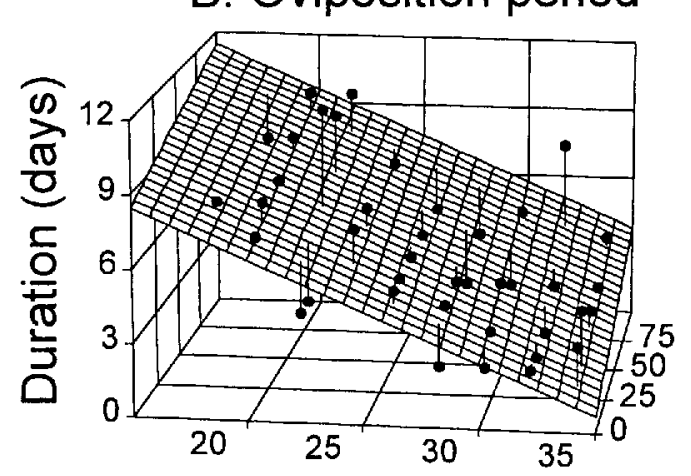

C. Post-oviposition period

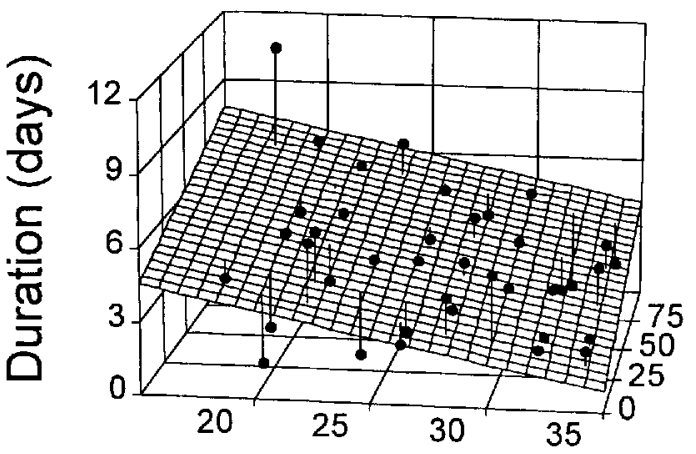

D. Fecundity

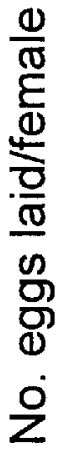

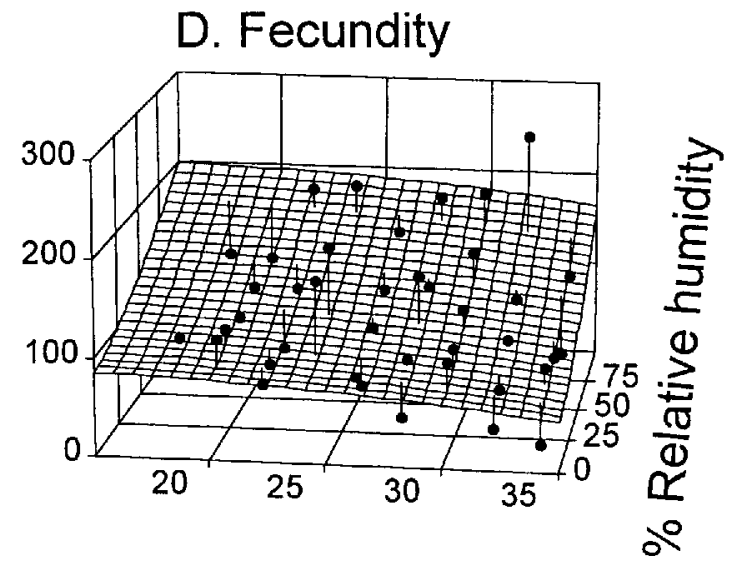

Temperature $\left({ }^{\circ} \mathrm{C}\right)$

Fig. 2. Effects of temperature and relative humidity on (A) male longevity; (B) duration of the oviposition period; (C) duration of the post-oviposition period; and (D) fecundity of C. cautella. Circles, observed data (from Nawrot 1979a); response surface, fitted equation (see Table 1). Drop lines indicate whether observed data are above or below the response surface, not standard errors.

warehouse after 8 wk of storage was $24^{\circ} \mathrm{C}$. We started the simulation with 1,725 adults of each sex so that the resulting adults trapped in the simulation matched the maximum number caught during the 1st peak of trap catch in the warehouse. We did not know the actual number of insects in the peanuts at the beginning of the storage period, so we selected this starting number of adults by running simulations and varying temperature regimes and initial number of adults until we found a combination that matched the number caught during the lst peak of trap catch in the warehouse. After the initial $8 \mathrm{wk}$, we used recorded ambient air temperatures and relative humidities in the simulation.

We assumed that $15 \%$ of adults present on any given day were caught in traps, based on a simplification of a previous trapping study (Hagstrum and Stanley 1979). Adults were not caught in traps on days when the temperature was $<13.4^{\circ} \mathrm{C}$ because Kirkpatrick et al. (1972) indicated that catches dropped significantly when ambient temperatures reached this level.
Malathion was applied in the warehouse as a surface treatment during the last week of each month of storage. Because we do not have data to develop a model of the effects of malathion on almond moth survivorship, we adjusted survivorship in the simulations so that the height of simulated trap catch peaks would match observed peaks. We applied malathion in the simulations on 27 October and adults were killed by the malathion until reapplication on 28 November, starting with $52 \%$ survival at each time step and linearly increasing to $92 \%$ survival at each time step on 27 November. Survival was the same for the reapplication.

We also used data from Hagstrum and Stanley (1979) to determine the validity of the model for stored peanuts. They trapped moths with suction traps in empty and stocked peanut warehouses in Florida from 26 April 1976 through March 1977. They released marked moths and determined recapture rates several times during the study. They started trapping shortly after the previous year's peanuts were removed from 
Table 1. Parameters (mean \pm SEM) for equations describing effects of temperature and relative humidity on life history of almond moths

\begin{tabular}{|c|c|c|c|c|}
\hline Response variable $(y)$ & Predictor variables $(x)$ & Parameter value & $r^{2}$ & $n$ \\
\hline \multicolumn{5}{|l|}{ Development time (days) } \\
\hline \multirow[t]{4}{*}{$\mathrm{Egg}^{\mathrm{n}}$} & Intercept & $51.35 \pm 1.414$ & 0.97 & 77 \\
\hline & Temp, ${ }^{\circ} \mathrm{C}$ & $-3.078 \pm 0.1123$ & & \\
\hline & Temp ${ }^{2}$ & $0.04939 \pm 0.002169$ & & \\
\hline & Relative humidity, $\%$ & $-0.006950 \pm 0.002674$ & & \\
\hline \multirow[t]{4}{*}{$\mathrm{Larvi}^{b}$} & Intercept & $739.9=30.06$ & 0.97 & 56 \\
\hline & Temp, ${ }^{\circ} \mathrm{C}$ & $-42.80 \pm 2.397$ & & \\
\hline & Temp $^{2}$ & $0.6783 \pm 0.04722$ & & \\
\hline & Relative humidity, \% & $-0.3740 \pm 0.04551$ & & \\
\hline \multirow[t]{4}{*}{ Pupa } & Intercept & $105.8 \pm 2.692$ & 0.98 & 56 \\
\hline & Temp, ${ }^{\circ} \mathrm{C}$ & $-6.448 \pm 0.2125$ & & \\
\hline & Temp ${ }^{2}$ & $0.1042 \pm 0.0041 .43$ & & \\
\hline & Relative humidity, $\%$ & $-0.003830 \pm 0.003854$ & & \\
\hline \multicolumn{5}{|l|}{ Mortality, \% } \\
\hline \multirow[t]{5}{*}{$\mathrm{Egg}^{d}$} & Intercept & $-1.179 \pm 0.2366$ & 0.48 & 77 \\
\hline & Temp, ${ }^{\circ} \mathrm{C}$ & $0.1464 \pm 0.01880$ & & \\
\hline & Temp ${ }^{2}$ & $-0.002812 \pm 0.0003637$ & & \\
\hline & Relative humidity, \% & $0.004851 \pm 0.001936$ & & \\
\hline & Relative humidity ${ }^{2}$ & $0.00003121 \pm 0.00001904$ & & \\
\hline \multirow[t]{4}{*}{ Larvit ${ }^{t}$} & Intercept & $-0.4731 \pm 0.3502$ & 0.44 & 54 \\
\hline & Temp, ${ }^{\circ} \mathrm{C}$ & $0.06558 \pm 0.02757$ & & \\
\hline & Temp $^{2}$ & $-0.001468 \pm 0.0005353$ & & \\
\hline & Relative humidity, \% & $0.002715 \pm 0.0005143$ & & \\
\hline \multirow[t]{4}{*}{ Pupat } & Intercept & $-0.8428 \pm 0.4390$ & 0.27 & 51 \\
\hline & Temp, ${ }^{\circ} \mathrm{C}$ & $0.1321 \pm 0.03432$ & & \\
\hline & Temp ${ }^{2}$ & $-0.002607 \pm 0.0006634$ & & \\
\hline & Relative humidity, $\%$ & $0.00007165 \pm 0.0007304$ & & \\
\hline \multicolumn{5}{|l|}{ Longevity (days) } \\
\hline \multirow[t]{3}{*}{ Male } & Intercept & $9.189 \pm 0.5570$ & 0.79 & 56 \\
\hline & Temp ${ }^{2}$ & $-0.007213 \pm 0.0006058$ & & \\
\hline & Relative humidity, \% & $0.03251 \pm 0.005448$ & & \\
\hline \multirow[t]{3}{*}{ Ovipositing female $^{f}$} & Intercept & $14.28 \pm 1.396$ & 0.67 & 40 \\
\hline & Temp, ${ }^{\circ} \mathrm{C}$ & $-0.3870 \pm 0.04889$ & & \\
\hline & Relative humidity, \% & $0.03023 \pm 0.008790$ & & \\
\hline \multirow[t]{3}{*}{ Post-ovipositing female ${ }^{f}$} & Intercept & $7.337 \pm 1.417$ & 0.43 & 40 \\
\hline & Temp, ${ }^{\circ} \mathrm{C}$ & $-0.1840 \pm 0.04962$ & & \\
\hline & Relative humidity, $\%$ & $0.03195 \pm 0.008921$ & & \\
\hline \multirow{3}{*}{$\begin{array}{l}\text { Fecundity } \\
\quad \text { (lifetime eggs/female) }\end{array}$} & Intercept & $88.85 \pm 15.15$ & 0.46 & 40 \\
\hline & Temp, ${ }^{\circ} \mathrm{C}$ & $-0.0008585 \pm 0.0005580$ & & \\
\hline & Temp ${ }^{2}$ & $0.1128 \pm 0.02127$ & & \\
\hline
\end{tabular}

\footnotetext{
${ }^{a}$ Duration of the egg stage was set to that predicted at $38^{\circ} \mathrm{C}$ if temperature exceeded $38^{\circ} \mathrm{C}$ during a simulation and was not allowed to drop below $2.23 \mathrm{~d}$ to ensure stability of the distributed delay.

${ }^{b}$ Duration of the larval stage was set to that predicted at $36^{\circ} \mathrm{C}$ if temperature exceeded $36^{\circ} \mathrm{C}$ during a simulation, was set to that predicted at $16^{\circ} \mathrm{C}$ if temperature dropped below $16^{\circ} \mathrm{C}$ during a simulation, and was not allowed to drop below $31.89 \mathrm{~d}$ to ensure stability of the distributed delay.

CDuration of the pupal stage was set to that predicted at $36^{\circ} \mathrm{C}$ if temperature exceeded $36^{\circ} \mathrm{C}$ during a simulation and was not allowed to drop below $5.82 \mathrm{~d}$ to ensure stability of the distributed deliny.

"Survivorship was not allowed to drop below 0 in simulations.

" Male longevity wiss set to that predicted at $35^{\circ} \mathrm{C}$ if temperature exceeded $35^{\circ} \mathrm{C}$ during a simulation and was not allowed to drop below 1.41 $\mathrm{d}$ to ensure stability of the distributed delay.

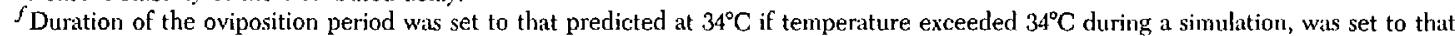
predicted at $18^{\circ} \mathrm{C}$ if temperature dropped below $18^{\circ} \mathrm{C}$ during a simulation, and was not allowed to drop below $2 \mathrm{~d}$ to ensure stability of the distributed delay.

${ }^{*}$ Duration of the post-oviposition period was set to that predicted at $34^{\circ} \mathrm{C}$ if temperature exceeded $34^{\circ} \mathrm{C}$ during a simulation, was set to that predicted at $18^{\circ} \mathrm{C}$ if temperature dropped below $18^{\circ} \mathrm{C}$ during a simulation, and was nat allowed to drop below $1 \mathrm{~d}$ to ensure stability of the distributed delay.

"Fecundity was 0 in the simulations when temperature was $<18^{\circ} \mathrm{C}$ or $>34^{\circ} \mathrm{C}$.
}

storage. More peanuts were loaded into storage after several months. The peanuts were fumigated with phosphine during the study and removed from the warehouse near the end of the study.

We used recorded ambient air temperatures in the simulation, and relative humidity was constant at $70 \%$. We added newly emerged adult males and females over a 7 -wk period to initialize the simulation: 16,14 , $19,39,50,46$, and 40 of each sex per day for week 3-9. Numbers were chosen to match the 1 st observed peak of trap catch by running numerous simulations because we did not know the actual infestation rate. We input adults over a 7 -wk period, rather than at one time as in the lst simulation, because in this study the previous year's peanuts had already been in storage for $\leq 6$ mo before trapping was started, and there should have been almond moths in all stages present in residual peanuts at the initiation of trapping even though the bulk of the peanuts had been removed from storage. Based on observed recapture rates, $7 \%$ of females 
and $20 \%$ of males were trapped in the unstocked warehouse (after the previous year's peanuts were removed from storage) in the simulations, and $10 \%$ of females and $31 \%$ of males were trapped in the stocked warehouse.

Peanuts were fumigated with phosphine from day 211 to 215 in the simulations, and $90 \%$ of adults, $12 \%$ of pupae, and $10 \%$ of the oldest larvae present at each time step were killed. These rates were chosen to match the height of observed peaks of trap catch. We killed only older larvae in the simulation because they leave the peanuts to find a pupation site and would be exposed to the fumigant, which had been applied incorrectly by placing tablets on the surface of the peanut bulk rather than by probing the tablets into the peanuts. The fumigant probably would not have penetrated the peanut bulk to kill larvae in the peanuts. Over the 5-d fumigation period, these mortality rates would remove nearly $100 \%$ of the older larvae, pupae, and adults. Peanuts were unloaded from day 232 to 287 , and $1.4 \%$ of all insects present were removed along with the peanuts at each time step. Again, this removal rate was chosen to match the height of observed peaks because we did not know actual removal rates.

Model Validation on Citrus Pulp. Dried citrus pulp is used as animal feed, providing a market for a byproduct of citrus juice production. The pulp is obtained shortly after harvesting and processing, then dried, and moved into storage warehouses over a 1- to 2-mo period. We used data from Hagstrum and Sharp (1975) to determine whether our model might be useful for predicting almond moth population dynamics on dried citrus pulp. They used artificial pupation sites to monitor the larval population in a warehouse containing citrus pulp in Florida during 1973.

We ran the model for $8 \mathrm{wk}$ at $25^{\circ} \mathrm{C}$ to develop a mixed age structure to start the simulation. We input adults at the rate of $5,9,13,18$, and 10 of each sex per day during each of five $3-\mathrm{d}$ periods to match the number of larvae trapped during the lst peak of trap catch. The temperature regime during loading and the initial number of insects input per day were determined by running simulations until we found a combination that matched the lst peak of trap catch.

We decreased larval developmental time by $21 \%$ compared with development on peanuts, to match the generation time observed between the 1 st and 2 nd peaks because actual rate of development of almond moths on dried citrus pulp has not been determined under controlled conditions. The larva is the only stage that feeds on the dried citrus pulp, so we assumed that any delays in development caused by food type should be applied to the larval stage. Larvae entered diapause at different times: $1.3 \%$ during days $1-91,15 \%$ during days $92-140,34 \%$ during days $141-$ 196, and 50\% during days 197-252 (Hagstrum and Sharp 1975). These time periods correspond to the lst through 4th generations, respectively. Nineteen percent of diapausing larvae complete diapause each week in the simulation. We trapped $0.1 \%$ of the last larval stage ( 159 total larval stages) each day, because we would expect only the older larvae to be trapped as they search for a pupation site.

We included mortality due to Bacillus thuringiensis Berliner, a pathogenic bacterium, starting at $5.5 \%$ on day 113 and increasing linearly to $21 \%$ on day 182 (Hagstrum and Sharp 1975). Mortality remained at $21 \%$ throughout the rest of the simulation. We assumed that the bacterium killed only the 7 youngest larval stages.

Egg predation by the red flour beetle, Tribolium castaneum (Herbst) (Coleoptera: Tenebrionidae), and by the mite Blattisocius tarsalis (Berlese) (Mesostigmata: Ascidae) also was observed in the citrus warehouse. We simulated egg predation by killing $2.4 \%$ of eggs daily starting on day 127 and linearly increasing mortality to $8.4 \%$ by the end of the study: These mortality rates were chosen to match the height of simulated and observed peaks of trap catches.

Model Validation on Corn. We used data reported by Graham (1970a, b) to determine whether our model could be used to simulate almond moth population dynamics on stored corn (Zea mays L.). He used flight-interception traps to monitor adult population levels in a warehouse containing bagged corn in Kenya during 1966. The corn was placed into storage in May 1965, fumigated in June and again in December because of an increasing moth population, and the study began in January 1966. Moths were present when the study began, despite the fumigation a few weeks before the study. Egg predation by B. tarsalis was presumed to be a major factor determining almond moth population dynamics.

We started the simulation by running the model for $62 \mathrm{~d}$ at $23^{\circ} \mathrm{C}$ and $70 \% \mathrm{RH}$ to give a mixed age structure. This temperature was similar to that at the start of the warehouse study, and $62 \mathrm{~d}$ allowed a generation to be completed in the simulation before 1 January. Input was 7,$000 ; 4,000 ; 8,000 ; 20,000 ; 27,000 ; 3,000 ; 3,000$; 3,000 ; and 1,500 eggs per day for $9 \mathrm{wk}$, respectively, to match the emergence of the 1st generation moths in the warehouse. These numbers were obtained by running simulations at varying environmental conditions and with different numbers and stages of moths.

We used recorded grain temperatures for the simulation and $70 \% \mathrm{RH}$. We reduced larval developmental time by $40 \%$ (Nawrot 1979b) compared with clevelopment on peanuts. A small proportion $(0.1 \%)$ of adults present at the end of each day were trapped, to match peaks of trap catches observed in the warehouse. Egg mortality due to predation by $B$. tarsalis was $0 \%$ on day 80 and increased linearly to $43 \%$ each time step on day 158 , to match peaks of trap catches observed in the warehouse.

\section{Results and Discussion}

Model Validation on Peanuts. The observed data from the 1st peanut validation study (Kirkpatrick et al. 1972 ) indicated that 3 generations of moths may have developed during the trapping period, with peaks of trap catch around days 300,324 to 334 , and 344 (Fig. 


\section{A. Light traps - no malathion}

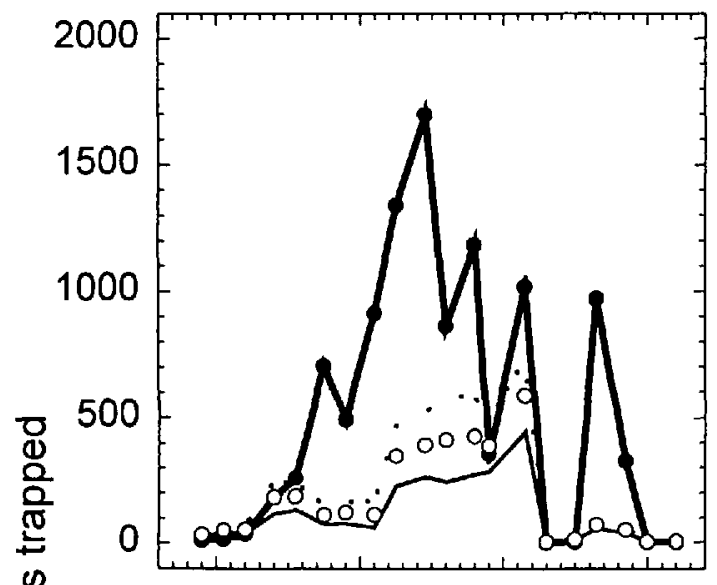

B. Light traps - malathion applied

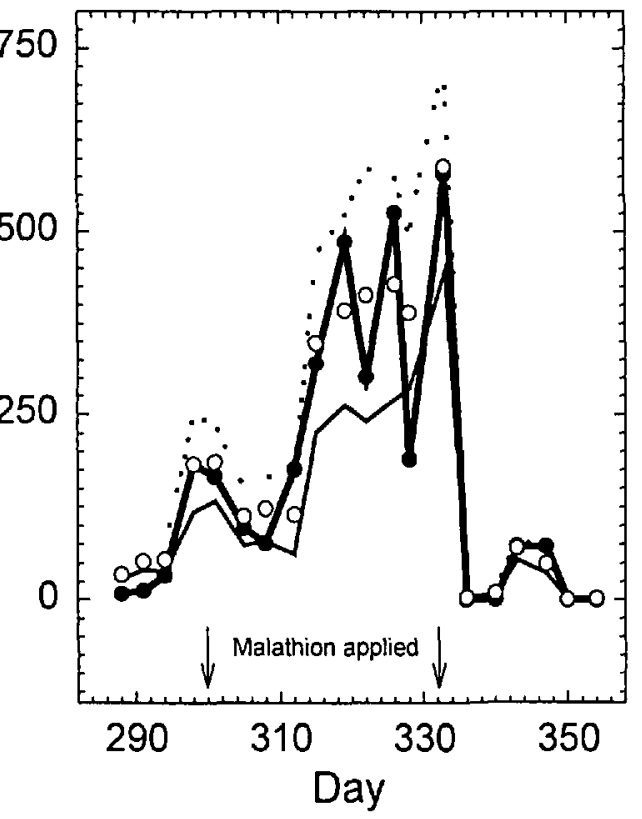

Fig. 3. Number of adult almond moths trapped in a peanut storage by using light traps (data from Kirkpatrick et al. [1972]) when (A) malathion is not applied in the simulation, and (B) malathion is applied in the simulation (timing of malathion applications indicated by arrows). Dashed line, number caught in ultraviolet light traps; thin solid line, number caught in green light traps; open circles, average number caught in traps; closed circles and thick solid line, simulated number trapped.

3A). We found that if we started simulations with eggs or ovipositing adults, no adults emerged during the simulations because of low temperatures during the trapping period. The model showed that the apparent peaks were not due to different generations of adults emerging but were due to changes in emergence or trapping efficiency caused by changes in environmental conditions. Thus, not even a single generation was completed during the study.
Our initial simulation, which did not include mortality due to malathion, overestimated the number of adults captured during the study (Fig. 3A). However, the timing of observed and simulated maximal and minimal catches was similar from day 327 to 354 . From days 300 to 304 (the end of October), trap catches increased in the simulations but dropped in the warehouse. This decrease in trap catch indicated that the malathion applications at the end of each month did affect population development in the trapping study and would have to be included in the simulations. Adding malathion-induced mortality to the simulation resulted in more accurate simulation of numbers of adults trapped and timing of maxima and minima (Fig. 3B). During times when the model results deviated most from observed trap catch (from day 319 to 328 ), the greatest variation in observed trap catch also occurred. Trapping efficiency may have varied during this time in response to environmental or management conditions during the trapping study, whereas trapping efficiency was constant in the simulation during this time.

Our model provided a good simulation of almond moth population development during the trapping study, despite some shortcomings in data because the study had not been designed for model validation. The data were reported as mean trap catches from 3 warehouses, even though environmental conditions were slightly different for each warehouse. The numbers of adults trapped were reported as means of the means of trap catches from the 3 warehouses with no measure of variance reported. Standard mean and variance relationships (Taylor 1984) indicate that trapping variance in this study would have been large; thus, confidence limits on trap catch would compensate for times when the simulation varied from the observed data.

The simulation indicated that very large numbers of adults must have entered the peanut storages during the trapping study. Kirkpatrick et al. (1972) found low levels of field infestation of the peanuts, yet trap catches sometimes exceeded 700 adults per day and probably only a small percentage of adults was trapped (Hagstrum and Stanley 1979). Little is known about rates of migration in and out of stored commodities, although large numbers of stored-product insects have been trapped outside grain storages indicating the possibility of extensive dispersal into storages (Throne and Cline 1994).

The model accurately predicted the timing of maxima and minima in trap catch on peanuts in the Hagstrum and Stanley (1979) study when fumigation and unloading of peanuts from the warehouse were not included in the simulation, but it did not accurately predict the numbers of insects present (Fig. 4A). The possibility of the development of 4 generations of almond moths, with peaks on days $50,84,105$, and 210 of storage, was indicated by the observed trap catches and by the simulations. Simulation indicated that the population would continue to increase after the 2nd observed peak (day 84), and that the $3 \mathrm{rd}$ peak (day 105) should have been higher than the 2 nd peak. We 


\section{A. Suction traps - no fumigant}

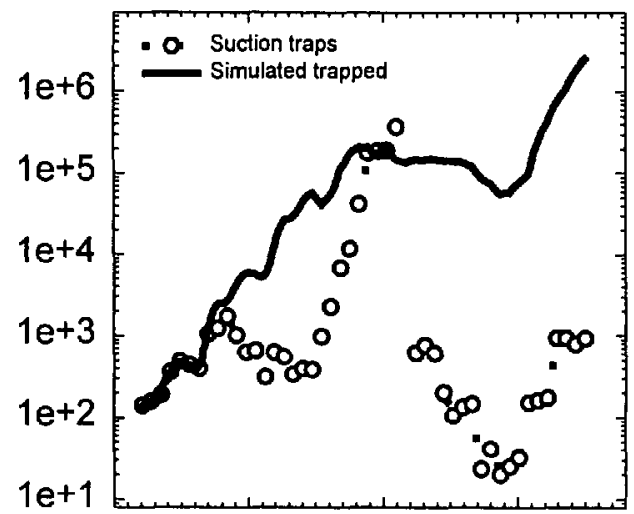

B. Suction traps - fumigant applied

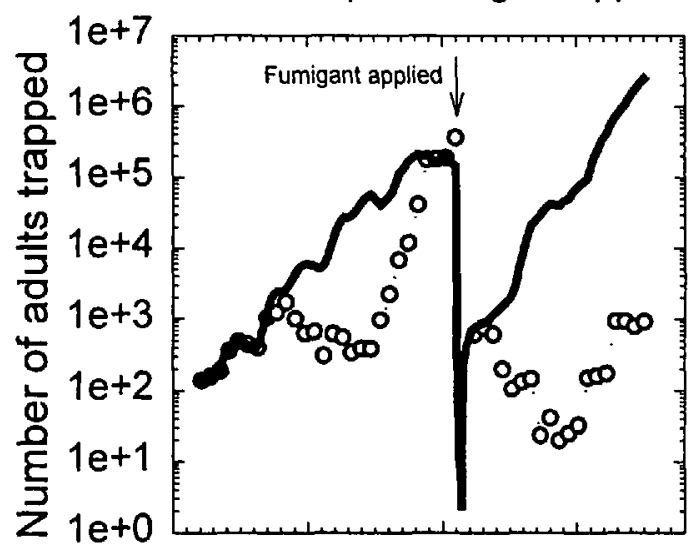

C. Suction traps - fumigant applied and peanuts unloaded

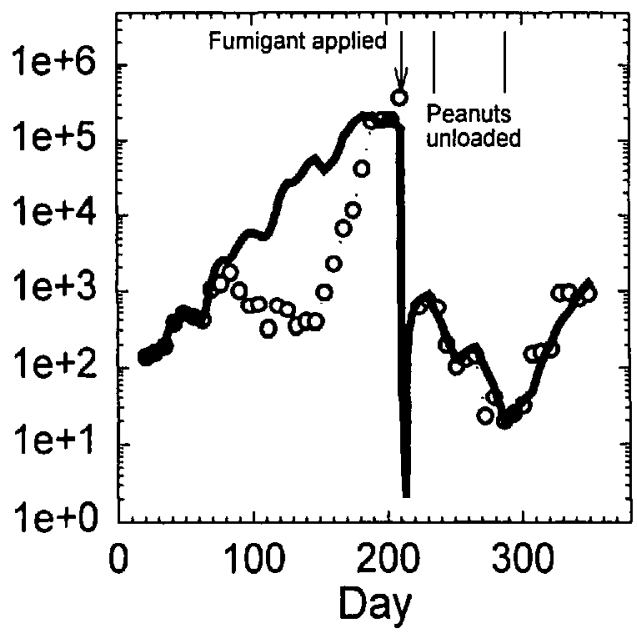

Fig. 4. Number of adult almond moths trapped in a peanut storage by using suction traps (data from Hagstrum and Stanley [1979]) when (A) no fumigant is applied and no peanuts are removed from storage; (B) fumigant is applied (timing indicated by arrow) but no peanuts are removed from storage; and (C) fumigant is applied (timing indicated by arrow) and peanuts are removed from storage (start and end of unloading indicated by straight lines). suggest that observed trap catch dropped during the 2nd peak because traps were moved close to the ceiling to prepare for loading of peanuts in the warehouse, thus changing trapping efficiency. We further suggest that the observed 3rd peak was low because peanuts were being loaded into the warehouse at this time so that loading activity and dust in the air reduced trap catch. Thus, the population actually must have been larger than the traps indicated during this time, or the highest peak (day 210) would not have been so large.

Population development in the simulations after day 210 followed the same pattern as observed with trapping. However, simulated catches were too high. Peanuts were fumigated in the warehouse on, or about, day 210 , and simulated fumigation resulted in a similar drop in population size after day 210 (Fig. 4B). However, subsequent population growth was still too rapid. Peanuts were removed from the warehouse from days 232 to 287 , resulting in an initial drop in trap catches and then an increase after unloading ceased. Unloading would remove insects from the warehouse with the peanuts and interfere with trapping. Inclusion of peanut removal in the simulations resulted in a close fit to observed data (Fig. 4C).

Model Validation on Citrus Pulp. Larval developmental time was adjusted to reflect generation time between the 1st and 2nd generations, but then the model accurately predicted timing of peak trap catch of the next 2 generations when diapause, $B$. thuringiensis-induced mortality, and egg predation were not included in the simulations (Fig. 5A). However, numbers of adults caught were overestimated in the simulations. Inclusion of diapause in the model improved the fit at peak 2 (day 122), but the height of subsequent peaks was still overestimated (Fig. 5B). Inclusion of $B$. thuringiensis-induced mortality in the model lowered the height of the last 2 peaks, but they were still too high (Fig. 5C). Inclusion of egg predation in the model resulted in a good fit to observed data (Fig. 5D). Hagstrum and Sharp (1975) indicated that their trap catches suggested that generation times were from 6 to $8 \mathrm{wk}$ during the study. Our simulation corroborates this finding. Our results indicate that the model is useful for simulating timing of almond moth population dynamics on dried citrus pulp.

Model Validation on Corn. Simulation of almond moth population development on corn was accurate until the 3rd peak of trap catch when mite-induced mortality was not included in the simulations (Fig. $6 \mathrm{~A})$. Timing of the $3 \mathrm{rd}$ peak was late in the simulation, and the number of adults trapped was overestimated. Inclusion of mite-induced mortality in the model corrected these inaccuracies (Fig. 6B). Graham (1970a) suggested that the timing of the peak catch of the 3rd generation was early, due to predation by mites, and our simulation corroborated this hypothesis.

Our model was useful for predicting almond moth population dynamics on several stored commodities. Generally, the timing of events was accurately predicted without modification to the model, but we had to include various mortality factors that were applied or observed in the published studies in the model to 

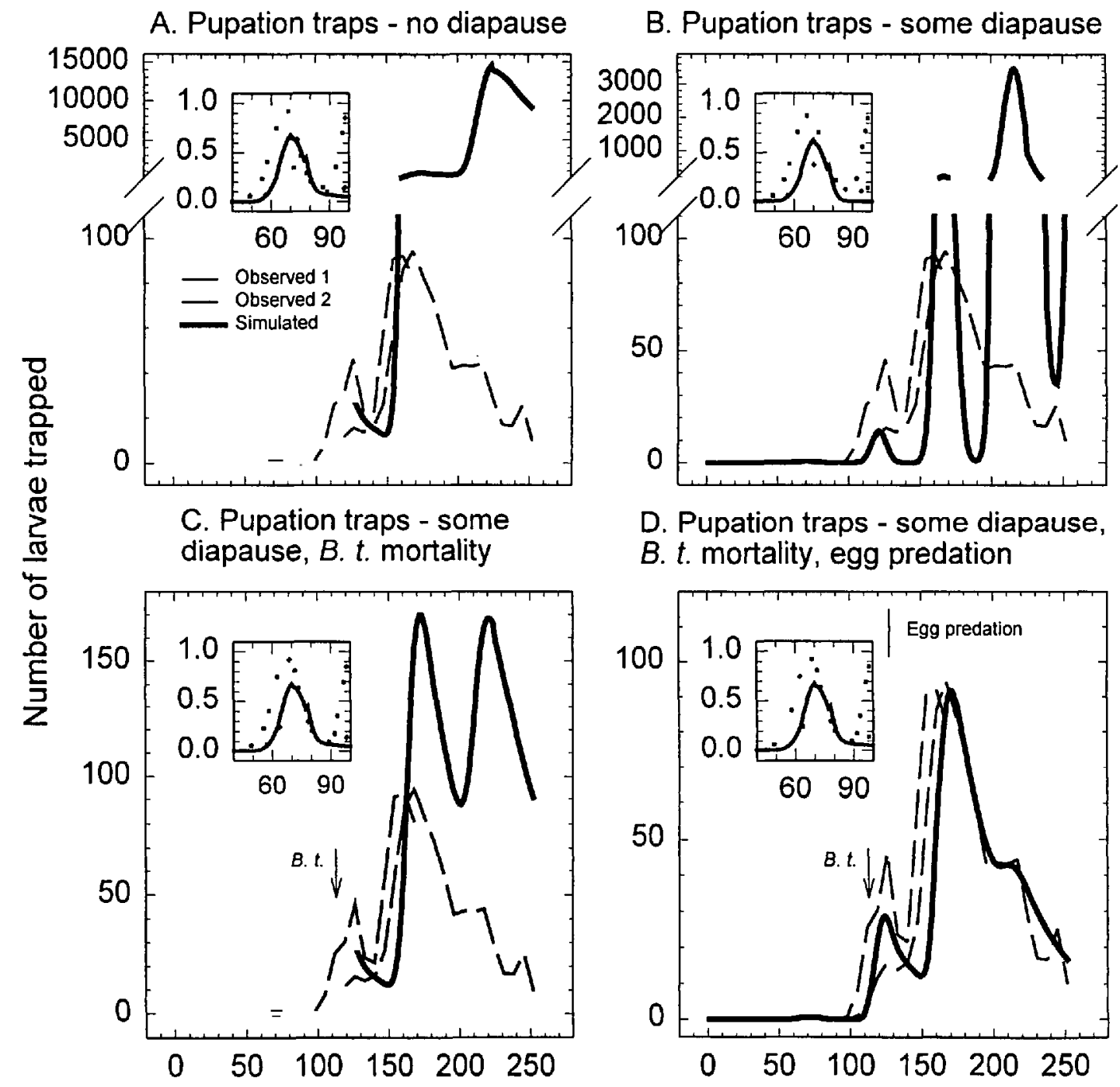

D. Pupation traps - some diapause,

B. $t$. mortality, egg predation

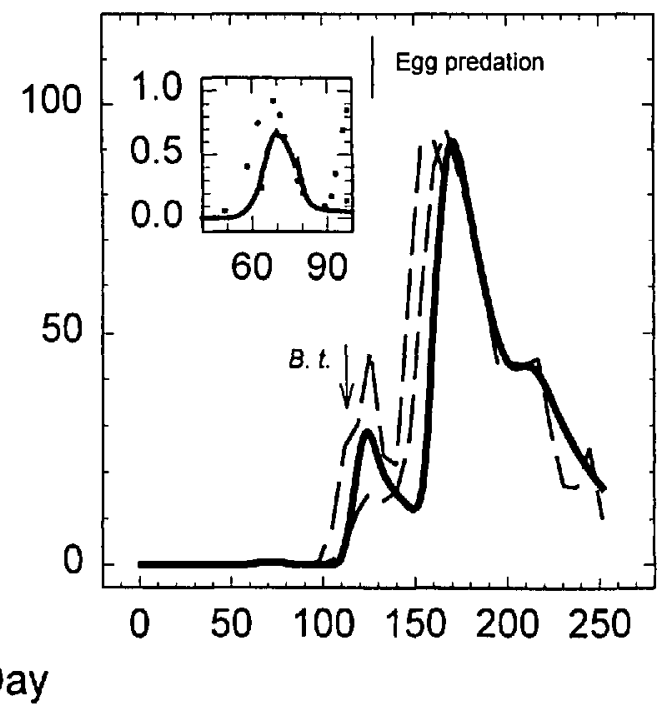

Fig. 5. Number of larval almond moths trapped in a dried citrus pulp storage by using pupation traps (data from Hagstrum and Sharp [1975]) when (A) no larvae enter diapause and no microbial-induced mortality or egg predation are included in the model; (B) some larvae enter diapause, but no microbial-induced mortality or egg predation are included in the model; (C) some larvae enter diapause and mortality induced by the bacterium $B$. thuringiensis is included in the model (initiation of microbial-induced mortality indicated by arrow), but when no egg predation is included in the model; and (D) some larvae enter diapause and mortality induced by $B$. thuringiensis and egg predation are included in the model (initiation of microbial-induced mortality indicated by arrow; initiation of egg predation indicated by line). Insets show blowups of trap catch early in the simulation when few insects were trapped.

match the observed numbers of insects trapped. However, the model still has limitations on use because we did not actually simulate the mechanics of control strategies, but rather mimicked the effects of control strategies based on observed data. Thus, the model cannot be used to simulate the effects of control strategies other than under the conditions of the particular validation studies. Simulation of control strategies awaits the collection of data describing the effects of environmental conditions on mortality caused by insecticides, microbes, mites, and red flour beetles.
This study emphasizes the usefulness of simulation models in interpreting ecological studies. Simulation indicated that trap catch in the study by Kirkpatrick et al. (1972) could be explained by low temperatures and malathion application and that only a partial generation of moths had developed during their study because of low temperatures. Hagstrum and Sharp (1975) suggested that almond moth population trends were influenced by diapause and predation. Graham (1970a) hypothesized that the timing of the peak catch of the 3rd generation of almond moths devel- 


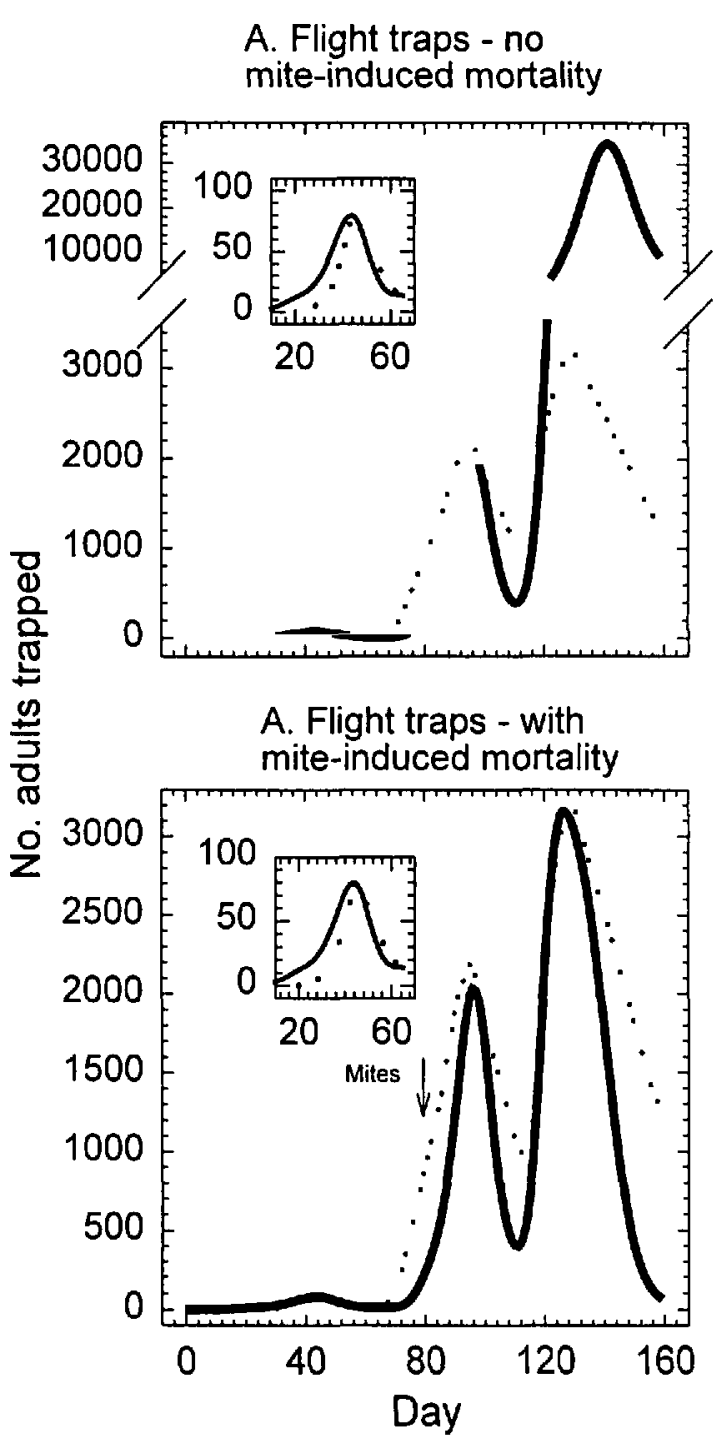

Fig. 6. Number of adult almond moths trapped in a corn storage by using flight traps (data from Graham [1970b]) when (A) no mite-induced mortality is included in the model, and (B) mortality induced by the mite $B$. tarsalis is included in the model (initiation of mite-induced mortality indicated by arrow). Insets show blowups of trap catch early in the simulation when relatively few insects were trapped. Dashed line, number caught in flight traps; solid line, simulated number trapped.

oping on corn occurred earlier than expected due to predation by mites. Our simulations corroborated these hypotheses.

Our results also indicate that a model developed for 1 food can be modified for use on another food by adjusting life history parameters. In our study, we only had to modify larval developmental time to accurately simulate development on citrus pulp and corn. Nawrot (1979b) provides data for development of almond moths on almonds (Prunus dulcis [Miller] Webb), barley (Hordeum vulgare L.), buckwheat (Fagopyrum sagittatum Gilbert), cocoa, oats (Avena spp.), rice (Oryza sativa $\mathrm{L}$.), sesame seeds (Sesamum orientale L.), sorghum (Sorghum bicolor Moench), and wheat (Triticum aestivum L.) under 1 environmental condition. Our model can be used to simulate population dynamics on each of these commodities, with minor modifications, although data for validation on these commodities is lacking.

In general, the model was robust in simulating the timing of events. Modifications that we made to the model to mimic observed data had little effect on timing of events, but rather affected the numbers of insects trapped. Given that the published studies were not designed with validation in mind and that there were many unmeasured factors in the validation studies (e.g., equipment moving peanuts in and out of storage, predation by mites and insects, changing environmental conditions, changing trapping efficiency), the simulations matched the timing of observed maxima and minima of trap catches remarkably well. The fit is even more remarkable when one considers that the published validation studies in only 1 case included confidence limits on trap catches.

The model should be useful as a tool for simulating almond moth population dynamics by using measured environmental conditions in a storage to monitor population development and to determine when control is required, or as a tool for prediction of the possibility of pest outbreak based on historical environmental conditions (see Throne 1995 for discussion of model uses). The model also would be useful for developing an expert system for aiding in making pest management decisions in citrus, corn, and peanut storages, as has been done for other stored commodities (Flinn and Hagstrum 1990).

Although the model simulates timing of almond moth population dynamics well, it does not include submodels of control methods. Thus, to simulate the effects of control methods on almond moth population dynamics and to use the model to optimize the use of available control methods, data for modeling the effects of controls on almond moths are required. These data include the effects of temperature and moisture on degradation of protectant insecticides used in peanuts and the effects of these insecticides and fumigants on almond moths. They also include the effects of temperature and moisture on B. tarsalis, B. thuringiensis, and T. castaneum population development, and their interactions with almond moths.

\section{Acknowledgments}

We thank Steve Brown (University of Georgia), Gerritt Cuperus (Oklahoma State University), David Margolies (Kansas State University), and Linda Mason (Purdue University) for their comments on an earlier version of the manuscript. 


\section{References Cited}

Amoako-Atta, B., and G. J. Partida. 1976. Sensitivity of almond moth pupae to ganma radiation (Lepidoptera: Pyralidae). J. Kans. Entomol. Soc. 49: 133-140.

Arbogast, R. T. 1981. Mortality and reproduction of Ephestia cautella and Plodia interpunctella exposed as pupae to high temperatures. Environ. Entomol. 10: 708-711.

Arthur, F. 1989. Pests of stored peanuts: toxicity and persistence of chlorpyrifos-methyl. J. Econ. Entomol. 82: $660-664$.

Arthur, F., J. L. Zettler, and W. R. Halliday. 1988. Insecticide resistance among populations of almond moth and Indianmeal moth (Lepidoptera: Pyralidae) in stored peanuts. J. Econ. Entomol. 81: 1283-1287.

de Abreu, J. M., R. N. Williams, and P. A. Rude. 1982. Revised bibliography of the almond moth (tropical warehouse moth), Ephestia cautella (Walker) (Lepidoptera: Phycitidae). Trop. Stored Prod. Inf. 44: 15-36.

Bowditch, T. G., and J. L. Madden. 1996. Spatial and temporal distribution of Ephestia cautella (Walker) (Lepidoptera: Pyralidae) in a confectionery factory: causal factors and management implications. J. Stored Prod. Res. 32: 123-I30.

Donahaye, E. J., S. Navarro, and M. Rindner. 1995. Low temperature as an alternative to fumigation for disinfecting dried fruit from three insect species. J. Stored Prod. Res. 31: 63-70.

Flinn, P. W, and D. W. Hagstrum. 1990. Stored grain advisor: a knowledge-based system for management of insect pests of stored grain. AI Appl. Nat. Res. Manage. 4: $44-52$.

Graham, W. M. 1970a. Warehouse ecology studies of bagged maize in Kenya-I. The distribution of adult Ephestia (Cadra) catutella (Walker) (Lepidoptera, Phycitidae). J. Stored Prod. Res. 6: 147-155.

$1970 \mathrm{~b}$. Warehouse ecology studies of bagged maize in Kenya-II. Ecological observations of an infestation by Ephestia (Cadra) cautella (Walker) (Lepidoptera, Phycitidae). J. Stored Prod. Res. 6: 157-167.

Hagstrum, D. W., and P. W. Flinn. 1990. Simulations comparing insect species differences in response to wheat storage conditions and management practices. J. Econ. Entomol. 83: 2469-2475.

Hagstrum, D. W., and J. E. Sharp. 1975. Population studies on Cadra cautella in a citrus pulp warehouse with particular reference to diapause. J. Econ. Entomol. 68: 11-14.

Hagstrum, D. W., and J. M. Stanley. 1979. Release-recapture estimates of the population density of Ephestia cautella (Walker) in a commercial peanut warehouse. J. Stored Prod. Res. 15: 117-122.

Hagstrum, D. W., and J. E. Throne. 1989. Predictability of stored-wheat insect population trends from life history traits. Environ. Entomol. 18: 660-664.

Keever, D. W., M. A. Mullen, J. W. Press, and R. T. Arbogast. 1986. Augmentation of natural enemies for suppressing two major insect pests in stored farmers stock peanuts. Environ. Entomol. 15: 767-770.

Kirkpatrick, R. L., D. Niffenegger, and D. L. Yancey. 1972. Detecting stored-product moths in a peanut warehouse by using light traps and larval traps. USDA-ARS Market. Res. Rep. 938.

Leesch, J. G., H. B. Gillenwater, and J. O. Woodward. 1974. Methyl bromide fumigation of shelled peanuts in bulk containers. J. Econ. Entomol. 67: 769-771.
Manetsch, T. J. 1976. Time-varying distributed delays and their use in aggregative models of large systems. IEEE Trans. Syst. Man Cybern. SMC-6: 547-553.

Nawrot, J. 1979a. Effect of temperature and relative humidity on population parameters for almond moth (Cadra cautella Wlk.) (Lepid. Phycitidae). Prace Nauk. Inst. Ochr. Roslin 21: 41-51.

1979b. Population parameters for almond moth (Cadra cautella Wlk.) (Lepidoptera: Phycitidae) reared on natural products. Prace Nauk. Inst. Ochr. Roslin 21: 53-60.

Prevett, P. F., F. P. Benton, D. R. Hall, R. J. Hodges, and R. dos S. Serodio. 1989. Suppression of mating in Ephestia cautella (Walker) (Lepidoptera: Phycitidae) using microencapsulated formulations of synthetic sex pheromone. J. Stored Prod. Res. 25: 147-154.

Rathore, Y. S., A. K. Bhattacharya, and G. C. Sachan. 1980. Use of concept of distance and group constellation for classifying the susceptibility of sorghum varieties to Ephestia cautella (Walker). J. Stored Prod. Res. 16: 39-42.

Riley, J. 1957. A survey of the build-up of infestation in bagged cocoa beans in store in westem Nigeria. Bull. Entomol. Res. 48: 75-78.

Ruesink, W. G. 1976. Status of the systems approach to pest management. Annu. Rev. Entomol. 21: 27-44.

Schesser, J. H. 1977. Fumigation of cereal grains and processed products in transport vehicles with phosphine from Detia Ex-B ${ }^{\text {(i) }}$. J. Econ. Entomol. 70: 199-201.

Storey, C. L. 1975. Mortality of three stored product moths in atmospheres produced by an exothermic inert atmosphere generator. J. Econ. Entomol. 68: 736-738.

Subramanyam, B., and D. W. Hagstrum. 1993. Predicting development times of six stored-product moth species (Lepidoptera: Pyralidae) in relation to temperature, relative humidity, and diet. Eur. J. Entomol. 90: 51-64.

Taylor, L. R. 1984. Assessing and interpreting the spatial distributions of insect populations. Annu. Rev. Entomol. 29: 321-357.

Throne, J. E. 1989. Effects of noncatastrophic control technologies that alter life history parameters on insect population growth: a simulation study. Environ. Entomol. 18: $1050-1055$

1995. Computer modeling of the population dynamics of stored-product pests, pp. 169-195. In D. S. Jayas, N.D.G. White, and W. E. Muir [eds.], Stored-grain ecosystems. Marcel Dekker, Inc., New York.

Throne, J. E., and L. D. Cline. 1994. Seasonal flight activity and seasonal abundance of selected stored-product $\mathrm{Co}$ leoptera around grain storages in South Carolina. J. Agric. Entomol. 11: 321-338.

[USDA] U. S. Department of Agriculture. 1994. Agricultural statistics 1994. USDA, National Agricultural Statistics Service, Washington, DC.

Vick, K. W., R. W. Mankin, R. R. Cogburn, M. Mullen, J. E. Throne, V. F. Wright, and L. D. Cline. 1990. Review of pheromone-baited sticky traps for detection of storedproduct insects. J. Kans. Entomol. Soc. 63: 526-532.

White, N.D.G., R. T. Arbogast, P. G. Fields, R. C. Hillman, S. R. Loschiavo, Bh. Subramanyam, J. E. Throne, and V. F. Wright. 1990. The development and use of pitfall and probe traps for capturing insects in stored grain. J. Kans. Entamol. Soc. 63: 506-525.

Received for publication 24 March 1997; accepted 8 December 1997 . 